\section{Neurochemistry study of spinal cord in non-human primate (Sapajus spp.)}

\author{
K.R. Torres-da-Silva, ${ }^{1,2}$ A.V. da Silva, ${ }^{2,3}$ \\ N.O. Barioni, ${ }^{2}$ G.W.L. Tessarin, ${ }^{1,2}$ \\ J.A. de Oliveira, ${ }^{1}$ E. Ervolino, ${ }^{1}$ \\ J.A.C. Horta-Júnior, ${ }^{2}$ C.A. Casatti ${ }^{1,2}$
}

'School of Dentistry of Araçatuba, Basic Sciences Department, São Paulo State University (UNESP), Araçatuba

2Biosciences Institute of Botucatu, Anatomy Department, São Paulo State University (UNESP), Botucatu

${ }^{3}$ School of Medicine, Federal University of Mato Grosso do Sul (UFMS), Três Lagoas, Brazil

\section{Abstract}

The spinal cord is involved in local, ascending and descending neural pathways. Few studies analyzed the distribution of neuromediators in the laminae of non-human primates along all segments. The present study described the classic neuromediators in the spinal cord of the non-human primate Sapajus spp. through histochemical and immunohistochemical methods. Nicotinamide adenine dinucleotide hydrogen phosphate-diaphorase (NADPH-d) method showed neuronal somata in the intermediolateral column (IML), central cervical nucleus (CCN), laminae I, II, III, IV, V, VI, VII, VIII and X, besides dense presence of nerve fibers in laminae II and IX. Acetylcholinesterase (AChE) activity was evident in the neuronal somata in laminae $\mathrm{V}, \mathrm{VI}$, VII, VIII, IX, CCN, IML and in the Clarke's column (CC). Immunohistochemistry data revealed neuronal nitric oxide synthase (nNOS) immunoreactivity in neuronal somata and in fibers of laminae I, II, III, VII, VIII, X and IML; choline acetyltransferase (ChAT) in neuronal somata and in fibers of laminae VII, VIII and IX; calcitonin gene-related peptide (CGRP) was noticed in neuronal somata of lamina IX and in nerve fibers of laminae I, II, III, IV, V, VI and VII; substance P (SP) in nerve fibers of laminae I, II, III, IV, V, VI, VII, VIII, IX, X, CCN, $\mathrm{CC}$ and IML; serotonin (5-HT) and vesicular glutamate transporter-1 (VGLUT1) was noticed in nerve fibers of all laminae; somatostatin (SOM) in neuronal somata of laminae III, IV, V, VI, VII, VIII and IX and nerve fibers in laminae I, II, V, VI, VII, X and IML; calbindin (Cb) in neuronal somata of laminae I, II, VI, VII, IX and $\mathrm{X}$; parvalbumin (PV) was found in neuronal somata and in nerve fibers of laminae III, IV, V, VI, VII, VIII, IX and CC; finally, gamma-amino butyric acid (GABA) was present in neuronal somata of laminae V, VI, VII, VIII, IX and X. This study revealed interesting results concerning the chemoarchitecture of the Sapajus spp. spinal cord with a distribution pattern mostly similar to other mammals. The data corroborate the result described in literature, except for some differences in CGRP, SP, Cb, PV and GABA immunoreactivities present in neuronal somata and in nerve fibers. This could suggest certain specificity for the neurochemistry distribution in this non-human primate species, besides adding relevant data to support further studies related to processes involving spinal cord components.

\section{Introduction}

The motor and sensory information processing is mainly dependent on neurotransmitters and neuropeptides released in the spinal cord. ${ }^{1}$ The control of nociceptive information involves neuropeptides such as somatostatin (SOM), substance P (SP) and calcitonin generelated peptide (CGRP) mainly localized in neurons present in the dorsal horn of the spinal cord. ${ }^{2,3}$ Neurons containing these neuropeptides modulate glutamate and gammaamino butyric acid (GABA) levels in synaptic terminals at the dorsal horn or may project to other areas of the central nervous system (CNS) associated with pain modulation, as observed in cats and monkeys. ${ }^{4}$

Serotonin (5-HT) is a neuromodulator mainly distributed in autonomic areas of the spinal cord, such as intermediolateral column (IML) and lamina X..$^{5}$ Acetylcholine is a classical neurotransmitter present in motor neurons projecting efferents to the somatic musculature and in IML neurons responsible for preganglionic innervation of autonomic ganglia. ${ }^{6,7}$ The distribution of acetylcholine has been indirectly and directly assessed by acetylcholinesterase enzyme (AChE) and choline acetyltransferase (ChAT), respectively. These enzymes enable a thorough neuroanatomic mapping, showing intense staining in motoneurons of the ventral horn and preganglionic neurons in the IML in rats and dogs..$^{8,9}$

The calcium-binding proteins, such as calbindin (Cb) and parvalbumin (PV), are important neuronal markers widely distributed in the CNS and peripheral nervous system, acting in the storage and/or transport of intracellular $\mathrm{Ca}^{2+}$ participating in synaptic modulation, especially in nociception. ${ }^{10,11} \mathrm{Cb}$ spinal cord distribution is evident in the superficial dorsal horn, participating in nociceptive pathways, while PV is concentrated in the ventral horn, including motoneurons, associated with motor functions. ${ }^{1,2}$ Studies show that the actions of
Correspondence: André Valério da Silva, School of Medicine, UFMS Federal University of Mato Grosso do Sul, Três Lagoas. Av. Ranulpho Marques Leal 3484, 79620-080, MS, Brazil.

Tel. +55.67.33453439.

E-mail: andre.valerio@ufms.br

Keywords: Spinal cord; immunohistochemistry; non-human primate; neuromediators.

Contributions: KRTS, AVS, study design, experimental procedures, histochemical and immunohistochemical processing, microscopic analysis, data collection, figures preparation, manuscript drafting; NOB, GWLT, manuscript drafting; JACHJ, EE, JAO, CAC, contribution to microscopic analysis, interpretation of data and manuscript drafting. All authors reviewed and contributed to the different draft versions, read and approved the final manuscript.

Acknowledgments: This study was supported by grants from the State of São Paulo Research Foundation (FAPESP - \#1999/10236-2; \#2012/03067-6; \#2012/08833-9; \#2008/02771-6; \#2013/25737-6) and a fellowship grant from the Brazilian Agency for Support and Evaluation of Graduate Education (CAPES).

Conflict of interest: the authors declare no conflict of interest.

Received for publication: 23 January 2016 . Accepted for publication: 17 August 2016.

This work is licensed under a Creative Commons Attribution-NonCommercial 4.0 International License (CC BY-NC 4.0).

(C) Copyright K.R. Torres-da-Silva et al., 2016

Licensee PAGEPress, Italy

European Journal of Histochemistry 2016; 60:2623 doi:10.4081/ejh.2016.2623

calcium-binding proteins are related to the coexistence of neurotransmitters or neuromodulators, as previously described through the colocalization with nitric oxide enzyme (NO), which collaborates with synaptic plasticity and spinal nociceptive regulation. ${ }^{12}$

The presence of nicotinamide adenine dinucleotide hydrogen phosphate-diaphorase (NADPH-d) enzyme corresponds to the nitric oxide synthase (NOS), which produces nitric oxide (NO). Thus, the distribution of NO is indirectly revealed through NADPH-d histochemistry. ${ }^{12}$ In rats, NADPH-d is colocalized with GABA in laminae I and II, similar to other mammalian species. ${ }^{3}$ However, NADPH-d mapping in the thoracic segment showed some differences between rodents and birds with no staining in autonomic preganglionic neurons in pheasants. This data suggests differences in the phylogenetic development, which is of 
great importance in neuroanatomical studies across species. ${ }^{1213}$ Thus, the use of neurochemical markers has helped morphological and functional characterization of neuronal populations in the spinal cord. ${ }^{14}$

Previous neuropeptide mapping studies in the spinal cord did not thoroughly describe their distribution along all laminae and were mainly limited to some segments, as observed in rats, cats, dogs, birds and monkeys, mainly in Old World monkeys. ${ }^{2,12,13,15-19}$ The Sapajus spp., previously described as Cebus apella, belongs to the group of New World monkeys and is extremely agile and active, presenting an important use of forelimbs to perform activities, such as digging in the soil, searching and breaking open objects. ${ }^{20}$ Their brain morphology is comparable to other Old World monkeys and they are an interesting experimental model used in cyto- and chemoarchitecture studies, ${ }^{21-23}$ although their spinal cord neuroanatomy has not yet been described. Therefore, the purpose of this study was to analyze the classical distribution of neuromediators in the Sapajus spp. spinal cord by using immunohistochemical and histochemical methods.

\section{Materials and Methods}

Three young male tufted capuchin monkeys (Sapajus spp.), housed in the Tufted Capuchin Monkey Procreation Center (Araçatuba School of Dentistry, São Paulo State University UNESP) were used in the present study. The experimental procedures followed the guidelines of the Brazilian Institute for the Protection of the Environment (IBAMA) and of the Institutional Ethical Committee for Animal Research (protocol number 02257-2012).

\section{Tissue preparation}

The monkeys were anesthetized, perfused and the spinal cords were collected and cryoprotected, as described in previous studies. ${ }^{24,25}$ Histological sections were obtained using a freezing microtome (coronal plane at $40 \mu \mathrm{m}$ ), stored in antifreeze solution at $-30^{\circ} \mathrm{C}$ until histochemistry and immunohistochemistry methods were performed.

\section{Histochemistry and immunohisto- chemistry}

The enzymatic activity of NADPH-d and AChE was assessed by the histochemistry method described in previous studies. ${ }^{21,26}$ Adjacent series were selected for immunohistochemistry. Free-floating sections were washed in phosphate buffer (0.1 M PBS, pH 7.4 ), pretreated in $0.3 \%$ hydrogen peroxide solution diluted in PBS and then incubated with avidin and biotin blocking solution (Avidin/Biotin Blocking Kit, SP-2001, Vector Laboratories Inc., Burlingame, CA, USA), for 30 min each. After PBS rinses, the sections were incubated overnight in a non-specific labeling blocking solution containing PBS, normal donkey serum and 1.5\% bovine serum albumin. After that, sections were incubated in

\section{Histochemistry/mmunohistochemistry} NADPH-d and AChE / nNOS and CHAT

primary antiserum (Table 1) and diluted in blocking solution (PBS $+0.03 \%$ triton X-100 + normal donkey serum), for $48 \mathrm{~h}$ at $4^{\circ} \mathrm{C}$. Next, the sections were incubated in biotinylated antibody and then in avidin-biotin complex (Vectastain, Kit Standard, PK-4000, Vector) for $1 \mathrm{~h}$ each at room temperature and the peroxidase activity was developed using diaminoben-

Immunohistochemistry
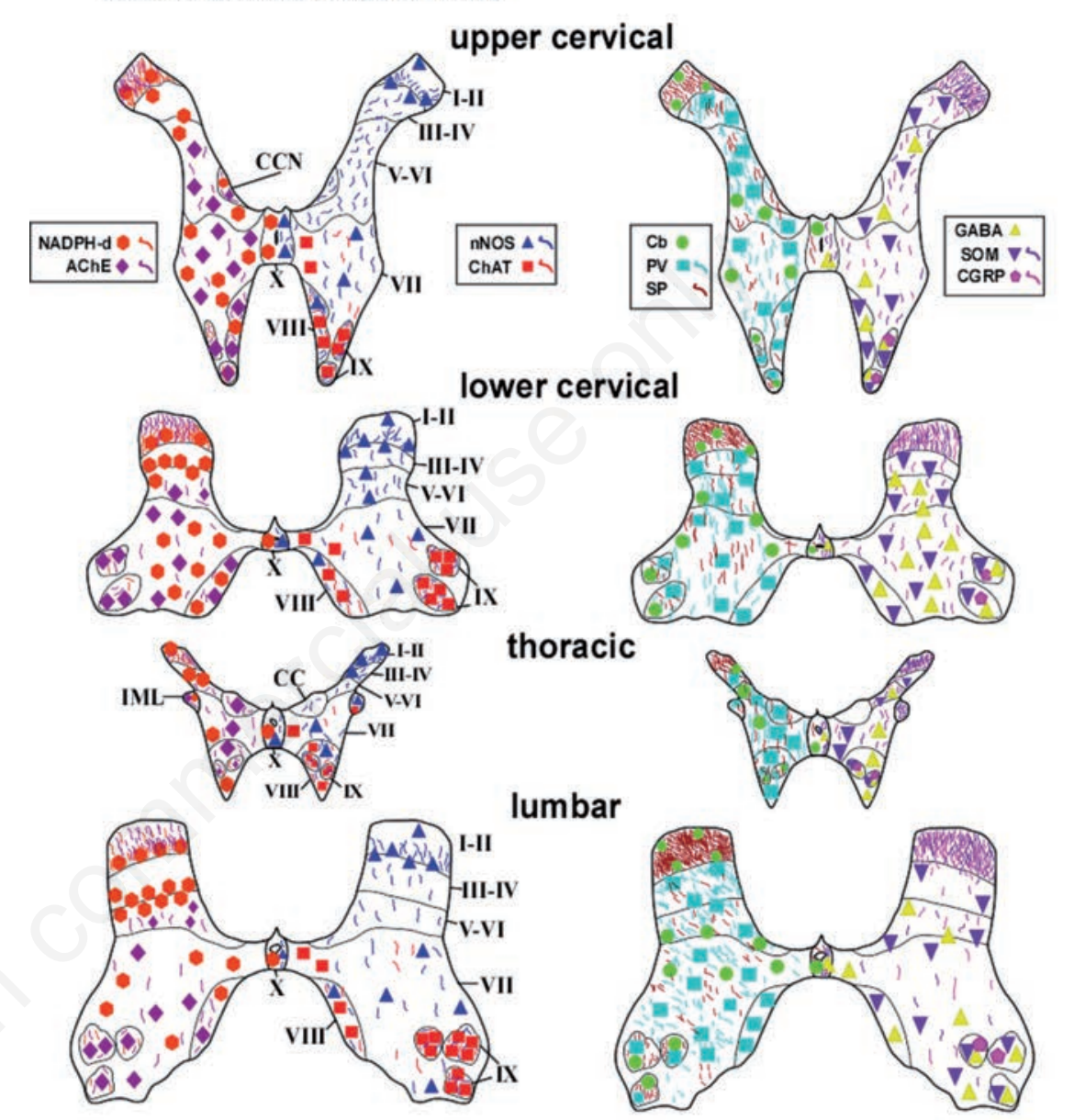

thoracic

lumbar

upper cervical 
zidine-chromogen reagent. Finally, the sections were mounted on gelatin coated slides, air dried, dehydrated in increasing ethanol solutions, delipified in xylene, mounted on DPX and cover slips. For control experiments all antibodies were omitted and no specific staining was observed. The sections were analyzed by light microscopy (Scope A1/Axioplan2, Carl Zeiss, Jena, Germany) and images were captured using a digital camera (Nikon Corporation, Tokyo, Japan) coupled to a Leica DMR microscope and NIS-Elements BR 3.0 software (Nikon Corporation).

\section{Results}

The histochemical methods used were adequate to reveal the laminar divisions and cytoarchitecture of the spinal cord of Sapajus spp. monkeys. The organization of laminae along the cord segments is shown in the schematic drawings (Figure 1). In general, all segments demonstrated the basic cytoarchitectonic organization observed in the spinal cord of mammals, such as distribution of neurons in all laminae and the presence of some neuronal groups. The latter were represented by: i) central cervical nucleus (CCN), localized in the medial part of laminae $\mathrm{V}$ and VII, at the upper cervical levels; ii) Clarke's column (CC), situated in the medial portion of laminae $\mathrm{V}$ and VI of the thoracic segment; iii) intermediolateral column (IML), situated in the lateral part of lamina VII of thoracic and upper lumbar segments. These variations were peculiar to spinal segments (Figure 1).

\section{Histochemistry}

NADPH-d. Neuronal somata were observed in the CCN and fibers of passage and possible terminals with varicosities were mostly evi-
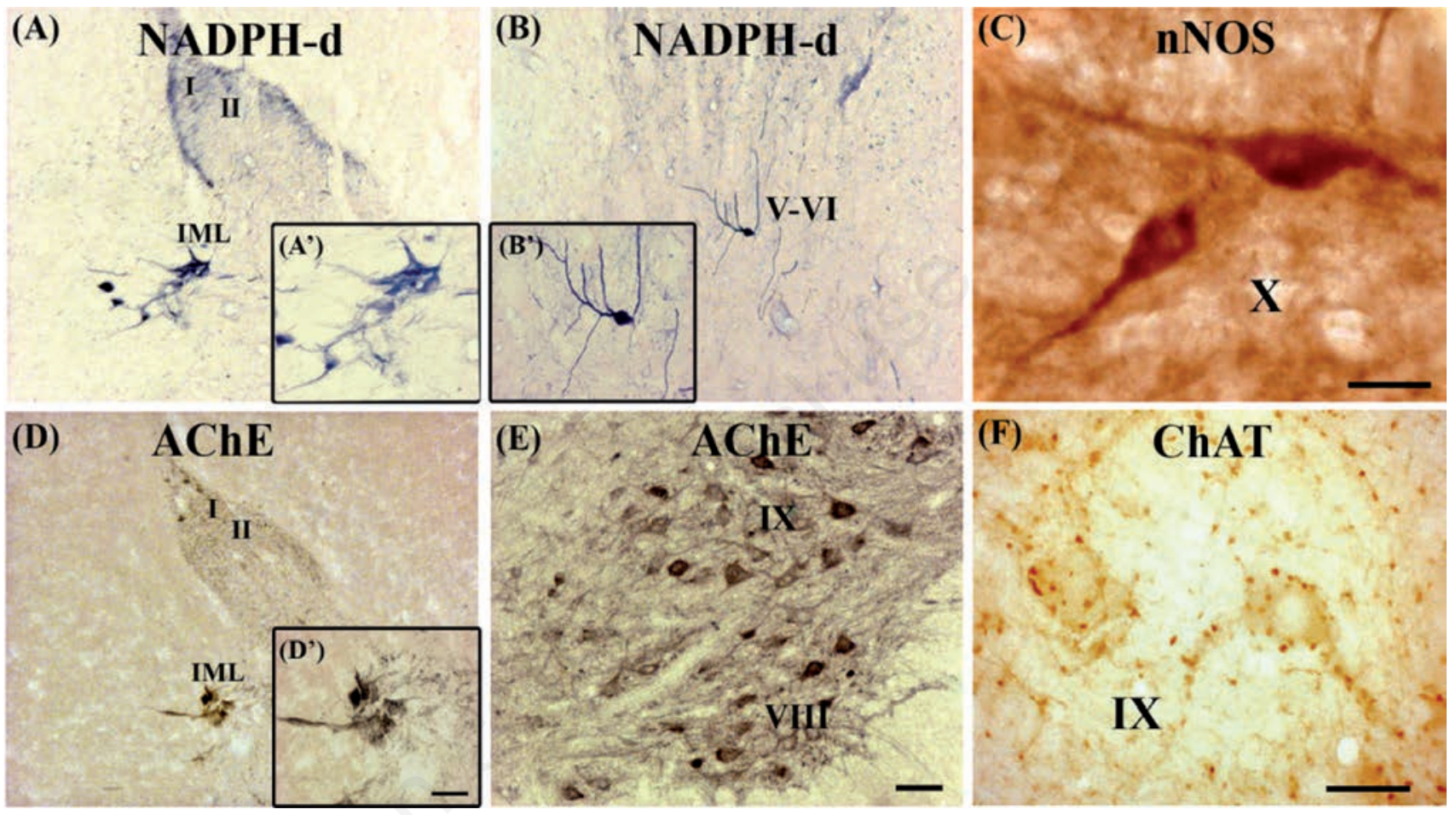

Figure 2. Light microscope photomicrographs showing chemioarchitecture of Sapajus spp. spinal cord. NADPH-d and AChE histochemistry is shown in A-B and D-E, respectively. A,D) Neuronal somata in IML from thoracic segment. B) NADPH-d neuronal somata within laminae V-VI from sacral segment; whereas E shows AChE motor neurons within laminae VIII and IX from lower cervical segment. nNOS-ir neuronal somata in lamina IV from lower cervical segment can be visualized in $\mathrm{C}$ and ChAT-ir terminals can be visualized within lamina IX from lumbar segment in F. Scale bars: A,B,D,E) $1000 \mu \mathrm{m}$; A',B',D', F) $500 \mu \mathrm{m}$; C) $200 \mu \mathrm{m}$.

Table 1. Description of commercial primary and secondary biotinylated antibodies used for mapping the spinal cord of Sapajus spp.

\begin{tabular}{|c|c|c|c|}
\hline Antibody & Source & Species & Dilution \\
\hline Serotonin (5-HT) & Immunostar ${ }^{\circledR} \# 20080$ & Rabbit & $1 / 20000$ \\
\hline GABA & Sigma ${ }^{\circledR}$ A2052 & Mouse & $1 / 1000$ \\
\hline Anti-vesicular glutamate transporter (VGLUT1) & Millipore® MAB 5502 & Mouse & $1 / 2000$ \\
\hline Calbindin (Cb) & Swant $($ \#CB38a & Mouse & $1 / 5000$ \\
\hline Parvalbumin (PV) & Sigma®P 3088 & Mouse & $1 / 5000$ \\
\hline Somatostatin (SOM) & Peninsula®T-4103 & Rabbit & $1 / 2000$ \\
\hline Calcitonin gene-related peptide ( $\alpha$-CGRP) & Peninsula $®$ T-4031.0400 & Rabbit & $1 / 3000$ \\
\hline Substance P (SP) & Chemicon®AB 1566 & Rabbit & $1 / 2000$ \\
\hline Anti-mouse biotinylated & Vector®\#BA-1000 & Goat & $1 / 800$ \\
\hline Anti-rabbit biotinylated & Vector®\#BA-9200 & Goat & $1 / 800$ \\
\hline
\end{tabular}


dent in laminae I and II (Figures 1 and 2A). Positively stained neuronal somata were also found in the IML and in laminae I, II, III, IV, V, VI, VII, VIII and X (Figures 1 and 2B).

AChE. Fibers were evident in laminae I and II (Figures 1 and 2D). Neuronal somata and fibers were observed in laminae V, VI and VII including CCN, IML and CC (Figures 1 and 2D). The ventral horn showed nerve fibers and neuronal somata evidently stained for AChE in lamina VIII and IX (Figures 1 and 2E).

\section{Immunohistochemistry}

nNOS. Neuronal nitric oxide synthaseimmunoreactive (nNOS-ir) fibers were observed in all laminae along the spinal cord. nNOS-ir neuronal somata were noted in laminae I, II, III, VII, VIII, X and in IML (Figures 1 and 2C). Neuronal somata were also observed in lamina $\mathrm{V}$, only at the lower cervical portion.

ChAT. Choline acetyltransferase-immunoreactive (ChAT-ir) neuronal somata and fibers were noticed in laminae VII, VIII and IX, with
ChAT-ir terminals surrounding motoneurons in lamina IX (Figures 1 and 2F).

CGRP. Calcitonin gene-related peptideimmunoreactive (CGRP-ir) nerve fibers and terminals were distributed in laminae I and II (Figures 1 and 3A). Few terminals were seen in laminae III, IV, V, VI and VII. Diffuse CGRPir neuronal somata were observed in lamina IX (Figures 1 and $3 A^{\prime}$ ).

SP. Substance P-immunoreactive (SP-ir) nerve fibers and terminals were noted in laminae I, II, III, IV, V, VI, VII, VIII, X, CC and IML
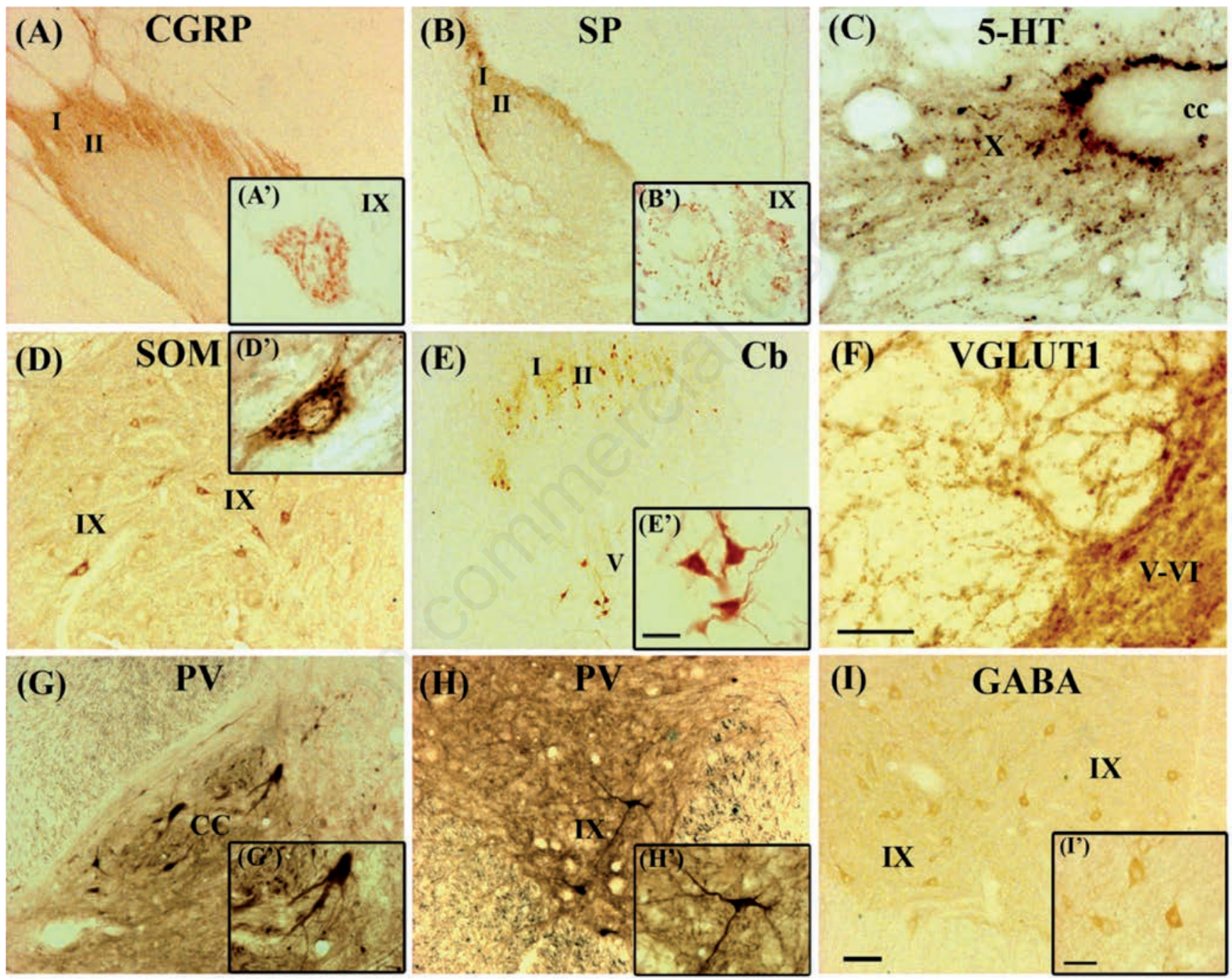

Figure 3. Light microscope photomicrographs showing neurochemistry of Sapajus spp. spinal cord. A) CGRP immunoreactivity in terminals within laminae I and II from upper cervical segment and a motor neuron from lamina IX (high magnification, A'). B) SP immunoreactivity in terminals within laminae I and II from thoracic segment. B') SP-ir motor neurons within lamina IX, surrounded by several terminals at high magnification. C) 5 -HT immunoreactivity observed in terminals within lamina X from thoracic segment. D) SOM immunoreactivity observed in neurons; whereas a neuronal somata is shown in lamina IX from lumbar segment at high magnification ( $\left.\mathrm{D}^{\prime}\right)$. E) $\mathrm{Cb}$ immunoreactivity in terminals and neuronal somata within lamina I and II from lumbar segment; whereas neuronal somata are shown in lamina $\mathrm{V}$ at high magnification ( $\left.E^{\prime}\right)$. F) VGLUT1 immunoreactivity in terminals within laminae V-VI, in transition region between white and gray matter from lower cervical segment. G,H) PV immunoreactivity in terminals and neuronal somata (high magnification in G' and $\mathrm{H}^{\prime}$ ) at Clarke's column and lamina IX, respectively, from thoracic segment. I) GABA immunoreactivity in neuronal somata distributed within lamina IX (high magnification in I'). Scale bars: A,B,D,E,G,H,I) $1000 \mu \mathrm{m} ; \mathrm{C}, \mathrm{F}, \mathrm{G}$ ',H', I') $500 \mu \mathrm{m}$; A', B', D', E') $200 \mu \mathrm{m}$. 
(Figures 1 and 3B). SP-ir terminals encircling the neuronal somata of motoneurons in lamina IX of all spinal segments (Figure 3B').

5-HT. Serotonin-immunoreactive (5-HT-ir) nerve fibers and terminals were homogeneously distributed along the spinal cord in all laminae; however, they were more evident in laminae I, X and IML (Figure 3C) and less evident in laminae II and VII.

SOM. Somatostatin-immunoreactive (SOMir) nerve fibers were noted in laminae I, II, V, VI, VII, X and IML. A small number of SOM-ir neuronal somata exhibiting immunoreactive cytosolic granules were evident in laminae III, IV, V, VI, VII, VIII and IX (Figures 1, 3D and 3D').

Cb. Calbindin-immunoreactive (Cb-ir) neuronal somata were distributed within laminae I, II and in the lateral portion of lamina $V$ with neuronal somata showing long axons and dendrites (Figures 3E and 3E'). Few and diffuse Cb-ir neuronal somata were observed in laminae VI, VII, IX and X (Figure 1).

VGLUT1. Vesicular glutamate transporter-1immunoreactive (VGLUT1-ir) nerve fibers and terminals were present throughout the segments with more evident staining in CCN, IML, lamina I and CC. Interestingly, fibers and terminals were noticed at the margin of the gray matter inside the lateral and ventral funiculus (Figure 3F).

PV. Parvalbumin-immunoreactive (PV-ir) neuronal somata and nerve fibers were localized in most laminae, excluding I, II and X (Figure 1). PV-ir fibers and neuronal somata with profuse axons and dendrites were distributed in the gray matter in CC (Figures $3 \mathrm{G}$ and $3 G^{\prime}$ ) and in laminae III, IV, V, VI, VII, VIII and IX (Figures 1, 3H and 3H').

GABA. Gamma-aminobutyric acidimmunoreactive (GABA-ir) neuronal somata were most evident in lower cervical and sacral segments in laminae V, VI, VII, VIII, IX and X (Figures 1 and 3I), while no immunostaining was observed in superficial laminae.

\section{Discussion}

The distribution of classical neuromediators and cytoarchitectonic arrangements in the spinal cord of Sapajus spp. monkey has not yet been described. This non-human primate exhibits spinal cord laminar cytoarchitectural organization similar to other mammals, including the Rexed's laminae study in cats, and some studies in Old World monkeys and humans. ${ }^{2,12,14,15,17,27-30}$ The spinal circuitry of mammals is characterized by its complexity compatible with the fine motor control of limbs and their feedback systems. The maintenance of a basic cytoarchitectonic and neurochemical structure of the spinal cord indicates a phylogenetically conserved evolutionary advantage. In parallel, rats and primates have comparable motor systems, which enable similar skilled movements of the limbs. ${ }^{31}$ In fact, the complexity of motor control probably exceeds the actions needed along the animal's lifetime. ${ }^{32}$ Hence, few differences among mammalian species would be expected in the spinal cord cytoarchitecture, although primates have an evident evolutionary difference that permitted the use of hands with an opposable set of digits. It is also important to mention that when primates are not moving, they use the forelimbs to perform other activities, such as digging in the soil and in tree holes, besides breaking objects open. ${ }^{20}$

The histochemistry method for NADPH-d along the spinal cord of Sapajus spp. monkey showed nerve fibers and possible nerve endings in lamina II and neuronal somata in laminae II-VIII, $\mathrm{X}$ and IML. NADPH-d activity indirectly indicates the possible localization of neuronal somata that produce nitric oxide (NO), which is an important neurotransmitter for modulation of the locomotion circuitry and autonomic nervous system control. ${ }^{33,34}$ For this reason, nitrergic neuronal somata distribution was also analyzed by immunohistochemistry using nNOS antibody. As expected, NADPH-d distribution was very similar to nNOS immunostaining. We observed that the distribution of nNOS-ir neuronal somata was not as extensive as NADPH-d, corroborating previous studies which indicated that some neuronal territories may not present colocalization. ${ }^{35,36}$

It has been demonstrated that cholinergic and non-cholinergic neurons have acetylcholinesterase enzyme $(\mathrm{AChE})^{7}$ and the immunohistochemical technique against choline acetyltransferase (ChAT) enzyme was able to confirm the cholinergic neurons ${ }^{37}$ Our histochemistry results showed AChE in neuronal somata and fibers of all laminae along the spinal cord, as evidenced in the rat spinal cord ${ }^{37}$ On the other hand, immunohistochemistry for ChAT showed immunostaining in neuronal somata of laminae VII, VIII and IX, which is in agreement with the literature demonstrating comparable data in rats, cats and monkeys. ${ }^{7,38}$ In addition, the presence of cholinergic terminals in motor neurons was evident in our immunohistochemistry results for ChAT, corroborating other studies. ${ }^{18}$ The present study also demonstrated AChE- and ChAT-stained neuronal somata in the IML, corresponding to the neurochemistry of preganglionic neurons. ${ }^{7,8,39}$ The data from the present study showed agreement with previous works describing the AChE distribution and ChAT mRNA in the spinal cord of small mammals, ${ }^{39}$ non-human primates and humans. ${ }^{7,18}$

CGRP-ir fibers were observed within lami- nae I and II of Sapajus spp., analogous to other species. ${ }^{2,40,41}$ CGRP has been localized in several areas of the central and peripheral nervous system. The superficial laminae of the spinal cord receives CGRP primary afferent projections from dorsal root ganglion neurons, participating in sensory systems of the spinal cord, including pain processing. ${ }^{40,42,43}$ Despite this evident distribution of CGRP-ir fibers in the spinal cord of Sapajus spp., it was verified that some neuronal somata within lamina IX presented granular immunoreactivity in the cytosol, corroborating another study indicating a possible CGRP role in motor systems as a trophic factor. ${ }^{2}$ A previous study described CGRP in neurons close to lamina IX, such as in laminae VII and VIII of dogs; ${ }^{2}$ however, we only observed neuronal somata CGRP-ir in lamina IX of Sapajus spp.

The glutamate amino acid is a widely excitatory neurotransmitter in the mammalian CNS. ${ }^{27}$ It is synthesized in the cytoplasm and transported along the axon in synaptic vesicles to the terminals. The glutamate distribution is very broad and its three carriers, VGLUT1, VGLUT2 and VGLUT3, can be visualized by immunohistochemistry. ${ }^{44,45}$ The present study mapped VGLUT1, since it was already characterized in the rat spinal cord. ${ }^{27,44,45}$ Several VGLUT1-ir terminals were observed in all monkey medullary segments and laminae, including lamina I. This finding partly corroborates data from the rat spinal cord, since the literature emphasizes the absence of VGLUT1 terminals in the rat lamina $I^{27,44}$ The VGLUT immunoreactive terminals in the superficial laminae establish synapse with SP nerve terminals from the dorsal root ganglion, possibly modulating sensory information. ${ }^{44}$ Furthermore, the literature emphasizes that VGLUT1 terminals are associated with proprioception pathways, as they are present in mechanoreceptor afferents and in many cutaneous afferents. ${ }^{45}$ Many VGLUT1 terminals in the spinal cord are probably projections from pyramidal cells of the neocortex that express VGLUT1 mRNA. ${ }^{45}$

Substance $\mathrm{P}$ is a neuropeptide involved in pain sensibility. ${ }^{46}$ Its immunoreactivity is present in neuronal somata in laminae I-III, $\mathrm{V}$ and IML, besides in terminals and fibers of superficial laminae in rats ${ }^{46}$ and cats. ${ }^{47}$ SP-ir neuronal somata were not found in the Sapajus spinal cord. In contrast, some terminals were observed within all laminae, with special abundance in the dorsal horn, IML and establishing possible contact with motoneurons of lamina IX, corroborating previous studies in man and monkey. ${ }^{48}$ Previous studies showed SP immunoreactivity in neuronal somata from the rat spinal cord, following colchicine treatment, which allows better visualization of neuropeptides in nervous tissue. ${ }^{46,49}$ 
Former studies indicated that $\mathrm{Cb}$ is mainly distributed in neurons within laminae I and II of dogs, ${ }^{11}$ rats $^{2}$ and Macaca fascicularis, ${ }^{16}$ in agreement with our results. Further studies in Macaca fascicularis showed Cb-ir neurons in lamina VII and nerve fibers in laminae I, II, VIII and IX, ${ }^{16}$ whereas our results demonstrated neuronal somata in laminae I, II, V, VI, VII, IX and $\mathrm{X}$. Another calcium-binding molecule, the parvalbumin, was observed in nerve fibers and neuronal somata of all laminae, excluding laminae I, II and X in contrast to studies in rats that describe the presence of $\mathrm{PV}$ in all laminae.$^{50} \mathrm{PV}$ staining delimitated the funiculus in the white matter as cuneiform funiculus and lateral corticospinal tract in Sapajus spp. PV neuronal somata were seen in the gray matter including the $\mathrm{CC}$, an area that projects afferents related to unconscious proprioception to the cerebellum, ${ }^{51,52}$ as previously verified in dogs. ${ }^{2}$

GABA is an inhibitory neurotransmitter present all over the CNS. ${ }^{53} \mathrm{GABA}$ is present in spinal cord superficial laminae in rats, acting as a pre-synaptic neurotransmitter in contact with nerve terminals, mostly glutamatergic. ${ }^{54,55}$ GABAergic mRNA expression was observed within neurons of lamina $\mathrm{X}$ in rats, in dorsal and lateral regions of the central canal, also known as a central autonomic area. ${ }^{56}$ Besides this, GABA plays an important role in learning and motor coordination during the developmental stages of the CNS. ${ }^{57}$ Our results showed GABA-ir neuronal somata in laminae V-X of all segments. Most of these results indicate that GABA localization in the spinal cord of Sapajus spp. is consistent with what has already been described in literature, possibly participating in autonomic ${ }^{56}$ and motor control..$^{57}$ Although no immunoreactivity was observed in superficial laminae of the Sapajus spinal cord, the employed antibody showed specificity in rats $^{58,59}$ and other studies described GABA in the dorsal horn of rhesus monkey. ${ }^{4}$ It is possible that the absence of immunostaining was due to the histological fixation step, impairing antigen recognition by the antibody.

Serotonin (5-HT) is a neuromediator of sensory processing ${ }^{60}$ and motor activity, ${ }^{61}$ contributing to wide functions in the spinal cord. 5 -HT is present in diffuse terminals and in some neurons in laminae VII and X of rats. ${ }^{5}$ In monkeys, 5-HT terminals are present in all laminae in the dorsal, ventral and lateral horns of the spinal cord ${ }^{62,63}$ and in some neurons in lamina $X .{ }^{64,65}$ The present results disclosed a diffuse and strong immunolabeling of 5-HT terminals in all segment levels and laminae, particularly in laminae I, X and IML, corresponding to varicose nerve fibers described in other monkeys. ${ }^{64,65}$ Some studies suggest that these terminals are originated from the raphe nucleus and ventrolateral medulla in primates. ${ }^{66}$
Somatostatin is a neuropeptide that is widely expressed in the CNS of mammals. ${ }^{28,67}$ Previous studies demonstrated that SOM is restricted to neuronal circuits in the dorsal horn. ${ }^{68,69}$ Furthermore, SOM was found in the dorsal root ganglia, suggesting an important modulatory role upon pain input, mainly the acute type ${ }^{67,68} \mathrm{SOM}$-ir fibers were clearly found in lamina $\mathrm{X}$ corroborating with other studies in monkeys ${ }^{64,70}$ and humans. ${ }^{28}$ Moreover, terminals in the IML were also described in the human spinal cord. ${ }^{71}$ SOM-ir neuronal somata in the dorsal (lamina III) and ventral horns (laminae VIII and IX) were also verified in other mammals. ${ }^{70}$ These data indicate that SOM probably participates not only in the modulation of sensory information of superficial laminae, but also in motor and in autonomic modulations in Sapajus spp.

It can be concluded that the neurochemical features found in the spinal cord of Sapajus spp. have similarities with other mammal species. Nevertheless, some results were different from the literature, such as CGRP, which was not observed in neuronal somata in laminae VII and VIII. In addition, SP was only found in nerve fibers and terminals; $\mathrm{Cb}$ was present in neuronal somata in laminae V, VI, VII and X; $\mathrm{PV}$ and GABA was absence in dorsal horn. These results showed some particularities in the distribution of classical neuromediators in this species, supporting further functional studies of the spinal cord in Sapajus spp.

\section{References}

1. Todd AJ. Neuronal circuitry for pain processing in the dorsal horn. Nat Rev Neurosci 2010;11):823-36.

2. Chang IY, Kim SW, Lee KJ, Yoon SP. Calbindin D-28k, parvalbumin and calcitonin gene-related peptide immunoreactivity in the canine spinal cord. Anat Histol Embryo. 2008;37:446-51.

3. Laing I, Todd AJ, Heizmann CW, Schmidt HH. Subpopulations of GABAergic neurons in laminae I-III of rat spinal dorsal horn defined by coexistence with classical transmitters, peptides, nitric oxide synthase or parvalbumin. Neuroscience 1994;61:123-32.

4. Alvarez FJ, Kavookjian AM, Light AR. Synaptic interactions between GABAimmunoreactive profiles and the terminals of functionally defined myelinated nociceptors in the monkey and cat spinal cord. J Neurosci 1992;12:2901-17.

5. Newton BW, Maley BE, Hamill RW. Immunohistochemical demonstration of serotonin neurons in autonomic regions of the rat spinal cord. Brain Res 1986;376:155-63.

6. Finkel E, Etlin A, Cherniak M, Mor Y, LevTov A, Anglister L. Neuroanatomical basis for cholinergic modulation of locomotor networks by sacral relay neurons with ascending lumbar projections. J Comp Neurol 2014;522:3437-55.

7. Woolf NJ. Cholinergic systems in mammalian brain and spinal cord. Prog Neurobiol 1991;37:475-524.

8. Gillberg PG, Askmark H, Aquilonius SM. Spinal cholinergic mechanisms. Prog Brain Res 1990;84:361-70.

9. Dai Y, Jordan LM. Multiple effects of serotonin and acetylcholine on hyperpolarization-activated inward current in locomotor activity-related neurons in Cfos-EGFP mice. J Neurophysiol 2010;104:366-81.

10. Zacharova G, Sojka D, Palecek J. Changes of parvalbumin expression in the spinal cord after peripheral inflammation. Physiol Res. 2009;58(3):435-42.

11. Yoshida S, Senba E, Kubota Y, Hagihira S, Yoshiya I, Emson PC, et al. Calcium-binding proteins calbindin and parvalbumin in the superficial dorsal horn of the rat spinal cord. Neuroscience 1990;37:839-48.

12. Freire MA, Tourinho SC, Guimaraes JS, Oliveira JL, Picanco-Diniz CW, Gomes-Leal W, et al. Histochemical characterization, distribution and morphometric analysis of NADPH diaphorase neurons in the spinal cord of the agouti. Front Neuroanat 2008;2:2.

13. Kluchova D, Rybarova S, Miklosova M, Lovasova K, Schmidtova K, Dorko F. Comparative analysis of NADPHdiaphorase positive neurons in the rat, rabbit and pheasant thoracic spinal cord. A histochemical study. Eur J Histochem 2001;45:239-48.

14. Polgar E, Sardella TC, Watanabe M, Todd AJ. Quantitative study of NPY-expressing GABAergic neurons and axons in rat spinal dorsal horn. J Comp Neurol 2011;519:1007-23.

15. Anelli R, Heckman CJ. The calcium binding proteins calbindin, parvalbumin, and calretinin have specific patterns of expression in the gray matter of cat spinal cord. $\mathrm{J}$ Neurocytol 2005;34:369-85.

16. Arvidsson U, Ulfhake B, Cullheim S, Ramirez V, Shupliakov 0, Hokfelt T. Distribution of calbindin D28k-like immunoreactivity (LI) in the monkey ventral horn: do Renshaw cells contain calbindin D28k-LI? J Neurosci 1992;12:718-28.

17. Dun NJ, Dun SL, Wu SY, Forstermann U, Schmidt HH, Tseng LF. Nitric oxide synthase immunoreactivity in the rat, mouse, cat and squirrel monkey spinal cord. Neuroscience 1993;54:845-57. 
18. Kobayashi Y, Okuda T, Fujioka Y, Matsumura G, Nishimura Y, Haga T. Distribution of the high-affinity choline transporter in the human and macaque monkey spinal cord. Neurosci Lett 2002;317:25-8.

19. Lima D, Avelino A, Coimbra A. Morphological characterization of marginal (lamina I) neurons immunoreactive for substance P, enkephalin, dynorphin and gamma-aminobutyric acid in the rat spinal cord. J Chem Neuroanat 1993;6:43-52.

20. Reynolds TR. Mechanics of increased support of weight by the hindlimbs in primates. Am J Phys Anthropol 1985;67:33549.

21. Cruz-Rizzolo RJ, Horta-Junior JAC, Bittencourt JC, Ervolino E, de Oliveira JA, Casatti CA. Distribution of NADPHdiaphorase-positive neurons in the prefrontal cortex of the Cebus monkey. Brain Res 2006;1083:118-33.

22. Cruz-Rizzolo RJ, De Lima MA, Ervolino E, de Oliveira JA, Casatti CA. Cyto-, myeloand chemoarchitecture of the prefrontal cortex of the Cebus monkey. BMC Neurosci 2011;12:6.

23. Horta-Junior JA, Tamega OJ, Cruz-Rizzolo RJ. Cytoarchitecture and musculotopic organization of the facial motor nucleus in Cebus apella monkey. J Anat 2004;204: 175-90.

24. Rosene DL, Roy NJ, Davis BJ. A cryoprotection method that facilitates cutting frozen sections of whole monkey brains for histological and histochemical processing without freezing artifact. J Histochem Cytochem 1986;34:1301-15.

25. Vasconcelos LA, Donaldson C, Sita LV, Casatti CA, Lotfi CF, Wang L, et al. Urocortin in the central nervous system of a primate (Cebus apella): sequencing, immunohistochemical, and hybridization histochemical characterization. J Comp Neurol 2003;463:157-75.

26. Satoh K, Armstrong DM, Fibiger HC. A comparison of the distribution of central cholinergic neurons as demonstrated by acetylcholinesterase pharmacohistochemistry and choline acetyltransferase immunohistochemistry. Brain Res Bull 1983;11:693-720.

27. Oliveira AL, Hydling F, Olsson E, Shi T, Edwards RH, Fujiyama F, et al. Cellular localization of three vesicular glutamate transporter mRNAs and proteins in rat spinal cord and dorsal root ganglia. Synapse 2003;50:117-29.

28. Schoenen J, Lotstra F, Vierendeels G, Reznik M, Vanderhaeghen JJ. Substance P, enkephalins, somatostatin, cholecystokinin, oxytocin, and vasopressin in human spinal cord. Neurology
1985;35:881-90.

29. Beal JA, Cooper MH. The neurons in the gelatinosal complex (Laminae II and III) of the monkey (Macaca mulatta): a Golgi study. J Comp Neurol 1978;179:89-121.

30. Rexed B. The cytoarchitectonic organization of the spinal cord in the cat. J Comp Neurol 1952;96:414-95.

31. Whishaw IQ. Did a change in sensory control of skilled movements stimulate the evolution of the primate frontal cortex? Behav Brain Res 2003;146:31-41.

32. Giszter SF, Hart CB, Silfies SP. Spinal cord modularity: evolution, development, and optimization and the possible relevance to low back pain in man. Exp Brain Res 2010;200:283-306.

33. Mechirova E, Domorakova I. NADPHdiaphorase activity in the spinal cord after ischemic injury and the effects of pretreatment with Ginkgo biloba extract (EGb 761). Acta Histochem 2002;104:427-30.

34. Marsala J, Orendacova J, Lukacova N, Vanicky I. Traumatic injury of the spinal cord and nitric oxide. Prog Brain Res. 2007;161:171-83.

35. Vizzard MA, Erdman SL, Roppolo JR, Forstermann U, de Groat WC. Differential localization of neuronal nitric oxide synthase immunoreactivity and NADPHdiaphorase activity in the cat spinal cord. Cell Tissue Res 1994;278:299-309.

36. Kluchova D, Klimcik R, Kloc P. Neuronal nitric oxide synthase in the rabbit spinal cord visualised by histochemical NADPHdiaphorase and immunohistochemical NOS methods. Gen Physiol Biophys 2002;21:163-74.

37. Kasa P. The cholinergic systems in brain and spinal cord. Prog Neurobiol 1986;26: 211-72.

38. Woolf NJ, Butcher LL. Cholinergic systems in the rat brain: IV. Descending projections of the pontomesencephalic tegmentum. Brain Res Bull 1989;23:519-40.

39. Oh JD, Woolf NJ, Roghani A, Edwards RH, Butcher LL. Cholinergic neurons in the rat central nervous system demonstrated by in situ hybridization of choline acetyltransferase mRNA. Neuroscience 1992;47: 807-22.

40. Shimoyama M, Tatsuoka H, Ohtori S, Tanaka K, Shimoyama N. Change of dorsal horn neurochemistry in a mouse model of neuropathic cancer pain. Pain 2005;114:221-30.

41. Gu XL, Yu LC. The colocalization of CGRP receptor and AMPA receptor in the spinal dorsal horn neuron of rat: a morphological and electrophysiological study. Neurosci Lett 2007;414:237-41.

42. Eftekhari S, Edvinsson L. Calcitonin generelated peptide (CGRP) and its receptor components in human and rat spinal trigeminal nucleus and spinal cord at $\mathrm{Cl}$ level. BMC Neurosci 2011;12:112.

43. Collin E, Mantelet S, Frechilla D, Pohl M, Bourgoin S, Hamon M, et al. Increased in vivo release of calcitonin gene-related peptide-like material from the spinal cord in arthritic rats. Pain 1993;54:203-11.

44. Li JL, Fujiyama F, Kaneko T, Mizuno N. Expression of vesicular glutamate transporters, VGluT1 and VGluT2, in axon terminals of nociceptive primary afferent fibers in the superficial layers of the medullary and spinal dorsal horns of the rat. J Comp Neurol 2003;457:236-49.

45. Todd AJ, Hughes DI, Polgar E, Nagy GG, Mackie M, Ottersen OP, et al. The expression of vesicular glutamate transporters VGLUT1 and VGLUT2 in neurochemically defined axonal populations in the rat spinal cord with emphasis on the dorsal horn. Eur J Neurosci 2003;17:13-27.

46. Ljungdahl A, Hokfelt T, Nilsson G. Distribution of substance P-like immunoreactivity in the central nervous system of the rat--I. Cell bodies and nerve terminals. Neuroscience 1978;3:861-943.

47. Takahashi T, Otsuka M. Regional distribution of substance $\mathrm{P}$ in the spinal cord and nerve roots of the cat and the effect of dorsal root section. Brain Res 1975;87:1-11.

48. de Lanerolle NC, LaMotte CC. The morphological relationships between substance $P$ immunoreactive processes and ventral horn neurons in the human and monkey spinal cord. J Comp Neurol 1982;207:30513.

49. Gamboa-Esteves FO, Kaye JC, McWilliam PN, Lima D, Batten TF. Immunohistochemical profiles of spinal lamina I neurones retrogradely labelled from the nucleus tractus solitarii in rat suggest excitatory projections. Neuroscience 2001;104:523-38.

50. Yamamoto T, Carr PA, Baimbridge KG, Nagy JI. Parvalbumin- and calbindin D28kimmunoreactive neurons in the superficial layers of the spinal cord dorsal horn of rat. Brain Res Bull 1989;23:493-508.

51. O'Halloran CJ, Kinsella GJ, Storey E. The cerebellum and neuropsychological functioning: a critical review. J Clin Exp Neuropsychol 2012;34:35-56.

52. Roostaei T, Nazeri A, Sahraian MA, Minagar A. The human cerebellum: a review of physiologic neuroanatomy. Neurol Clin 2014;32:859-69.

53. Todd AJ. Plasticity of inhibition in the spinal cord. Handb Exp Pharmacol 2015; 227:171-90

54. Gackiere F, Vinay L. Serotonergic modulation of post-synaptic inhibition and locomotor alternating pattern in the spinal 
cord. Front Neural Circuits 2014;8:102.

55. Heinke B, Ruscheweyh R, Forsthuber L, Wunderbaldinger G, Sandkuhler J. Physiological, neurochemical and morphological properties of a subgroup of GABAergic spinal lamina II neurones identified by expression of green fluorescent protein in mice. J Physiol 2004;560:249-66.

56. Deuchars SA, Milligan CJ, Stornetta RL, Deuchars J. GABAergic neurons in the central region of the spinal cord: a novel substrate for sympathetic inhibition. J Neurosci 2005;25:1063-70.

57. Ziskind-Conhaim L. Neuronal correlates of the dominant role of GABAergic transmission in the developing mouse locomotor circuitry. Ann N Y Acad Sci 2013;1279: 43-53.

58. Janssen SP, Truin M, Van Kleef M, Joosten EA. Differential GABAergic disinhibition during the development of painful peripheral neuropathy. Neuroscience 2011;184:183-94.

59. Janssen SP, Gerard S, Raijmakers ME, Truin M, Van Kleef M, Joosten EA. Decreased intracellular GABA levels contribute to spinal cord stimulation-induced analgesia in rats suffering from painful peripheral neuropathy: the role of $\mathrm{KCC} 2$ and $\mathrm{GABA}(\mathrm{A})$ receptor-mediated inhibition. Neurochem Int 2012;60:21-30.

60. Garcia-Ramirez DL, Calvo JR, Hochman S, Quevedo JN. Serotonin, dopamine and noradrenaline adjust actions of myelinated afferents via modulation of presynaptic inhibition in the mouse spinal cord. PLoS One 2014;9:e89999.

61. Slawinska U, Miazga K, Jordan LM. The role of serotonin in the control of locomotor movements and strategies for restoring locomotion after spinal cord injury. Acta Neurobiol Exp (Wars) 2014;74:172-87.

62. Kojima M, Takeuchi Y, Goto M, Sano Y. Immunohistochemical study on the localization of serotonin fibers and terminals in the spinal cord of the monkey (Macaca fuscata). Cell Tissue Res 1983;229:23-36.

63. Nicholas AP, Pieribone VA, Arvidsson U, Hokfelt T. Serotonin-, substance P- and glutamate/aspartate-like immunoreactivities in medullo-spinal pathways of rat and primate. Neuroscience 1992;48:545-59.

64. LaMotte CC. Lamina $X$ of primate spinal cord: distribution of five neuropeptides and serotonin. Neuroscience 1988;25: 639-58.
65. Lamotte CC, Johns DR, de Lanerolle NC. Immunohistochemical evidence of indolamine neurons in monkey spinal cord. J Comp Neurol 1982;206:359-70.

66. Jacobs BL, Azmitia EC. Structure and function of the brain serotonin system. Physiol Rev 1992;72:165-229.

67. Viollet C, Lepousez G, Loudes C, Videau C, Simon A, Epelbaum J. Somatostatinergic systems in brain: networks and functions. Mol Cell Endocrinol 2008;286:75-87.

68. Duan B, Cheng L, Bourane S, Britz 0, Padilla C, Garcia-Campmany L, et al. Identification of spinal circuits transmitting and gating mechanical pain. Cell 2014;159:1417-32.

69. Buck SH, Walsh JH, Yamamura HI, Burks TF. Neuropeptides in sensory neurons. Life Sci 1982;30:1857-66.

70. Burnweit C, Forssmann WG. Somatostatinergic nerves in the cervical spinal cord of the monkey. Cell Tissue Res 1979;200: 83-90.

71. Chung K, Briner RP, Carlton SM, Westlund KN. Immunohistochemical localization of seven different peptides in the human spinal cord. J Comp Neurol 1989;280:158-70. 